NOTES

\title{
Polyacetylene with Coumarin Containing Pendant Groups by Polymerization of 7-Propargyloxy-4-methylcoumarin
}

\author{
Hynek Balcar, Pavel Kubát, Marta PacovskA, ${ }^{*}$ and Vratislav Blechta** \\ J. Heyrovsky Institute of Physical Chemistry, Academy of Sciences of the Czech Rep., \\ Dolejškova 3, 182 23, Prague 8, Czech Republic \\ * Department of Physical and Macromolecular Chem., Charles University, \\ Albertov 2030, 12840 Prague 2, Czech Republic \\ **Institute of Chemical Process Fundamentals, Academy of Sciences of the Czech Rep., \\ 16502 Prague 6, Czech Republic
}

(Received May 17, 1999)

KEY WORDS Coumarin / Polyacetylene / Coordination Polymerization / Luminescence /

Coumarins (benzo-2-pyrons) are well known for physiological effects, fluorescence and electroluminescence. They are widely used as laser dyes and nowadays find applications as dopants in organic light-emitting diodes. ${ }^{1,2}$ Recently, several reports appeared, ${ }^{3-11}$ concerning possibility to incorporate coumarin molecules directly into polymer chains to prepare new progressive materials for optical purposes. Polyamides and polyesters with coumarin nucleus in the polymer main chain have been prepared and found to exhibit photoluminescence and electroluminescence in blue-green region. ${ }^{3-6}$ Metathesis polymerization of 7-[(2-norbornen-5-yl)methoxy]coumarin provided polynorbornene, which showed photoluminescence owing to methoxycoumarin pendant groups. ${ }^{7}$ Methacryloyloxyalkoxycoumarins have been polymerized and copolymerized to vinylic polymers and found applicable to electroluminescent devices. ${ }^{8.9}$ Nonlinear optical properties of polymethacrylates with coumarin groups have also been described. ${ }^{10}$ Poly $(p-$ phenyleneethynylene) with coumarin groups attached to the phenylene rings via flexible spacers exhibits enhanced luminescence as a result of energy transfer from coumarin side groups to the conjugated polymer backbone. ${ }^{11}$ However, according to our knowledge, no attempt has been made to prepare coumarin-containing polyacetylene, although substituted polyacetylenes with photo- and electroluminescence attract much attention. ${ }^{12}$ Probably, the main problem in this case is the proper selection of catalyst for the polymerization of coumarin-containing acetylenic monomers.

Previous studies ${ }^{13,14}$ reported the preparation of new polyacetylene type polymers by metathesis and insertion polymerizations of substituted phenyl propargyl ethers with molybdenum and palladium catalysts. This paper presents results on polymerization of 7-propargyloxy-4methylcoumarin $(\mathrm{PgCo})$ leading to a new polyacetylene with coumarin-containing side groups.

\section{EXPERIMENTAL}

\section{Materials}

$\mathrm{MoCl}_{5}$ (Aldrich, 99.9\%), $\mathrm{PdCl}_{2}$ (Aldrich, 99\%) were used as obtained. Tetrabutyltin, $\mathrm{Bu}_{4} \mathrm{Sn}$ (Koch Light) was distilled in vacuum. Preparation and purification of ethylaluminium dichloride, $\mathrm{EtAlCl}_{2}$ are described elsewhere. ${ }^{15} \mathrm{~N}, \mathrm{~N}$-Dimethylformamide (DMF) was dried with $\mathrm{P}_{2} \mathrm{O}_{5}$ and distilled under argon. Before use in polymerization experiments, it was degassed in vacuum. Benzene, after conventional purification, was refluxed with $\mathrm{NaH}$ in vacuum and degassed (for details see ref 16 ).

7-Propargyloxy-4-methylcoumarin (PgCo) was prepared by alkylation of 7-hydroxy-4-methylcoumarin with propargyl bromide. $3.52 \mathrm{~g}(20 \mathrm{mmol})$ of 7-hydroxy-4methylcoumarin (Aldrich, 97\%) was mixed with $17 \mathrm{~g}$ of anhydrous $\mathrm{Na}_{2} \mathrm{CO}_{3}$ (pulverized) and $3.3 \mathrm{~g}$ of $\mathrm{KI}$ (pulverized) in $40 \mathrm{~mL}$ of dry DMF. $3 \mathrm{~g}(20 \mathrm{mmol})$ of propargyl bromide (Aldrich, $80 \mathrm{wt} \%$ in toluene) were added and the reaction mixture was stirred at $60-70^{\circ} \mathrm{C}$ for $4.5 \mathrm{~h}$. After cooling, it was poured into $500 \mathrm{~mL}$ water, the precipitate was separated and after washing with $5 \% \mathrm{NaOH}$ (aq) and water it was dried in vacuum $\left(40^{\circ} \mathrm{C}\right)$. The product was purified by sublimation in vacuum. Yield $82 \%$., $\mathrm{mp}$ $135.5-137^{\circ} \mathrm{C}$. IR spectrum $(\mathrm{KBr}), \mathrm{cm}^{-1}: 3295(\equiv \mathrm{C}-\mathrm{H})$, 3060 (C-H arom.), 2960, 2920, 2860 (C-H aliph.), 1716 $(\mathrm{C}=\mathrm{O}),{ }^{1} \mathrm{H} \mathrm{NMR}\left(\mathrm{CDCl}_{3}\right), \delta \mathrm{ppm}: 2.37(\mathrm{~d}, 3 \mathrm{H}, \mathrm{Me}), 2.55$ (t, $1 \mathrm{H}$, acetylene), $4.73\left(\mathrm{~d}, 2 \mathrm{H}, \mathrm{CH}_{2}-\mathrm{O}\right), 6.12\left(\mathrm{q}, 1 \mathrm{H}, \mathrm{H}^{3}\right)$, $6.90\left(\mathrm{~m}, 2 \mathrm{H}, \mathrm{H}^{6}\right.$, and $\left.\mathrm{H}^{8}\right), 7.49\left(\mathrm{~m}, 1 \mathrm{H}, \mathrm{H}^{5}\right),{ }^{13} \mathrm{C} \mathrm{NMR}$ $\left(\mathrm{CDCl}_{3}\right), \delta \mathrm{ppm}: 18.57(\mathrm{Me}), 56.07\left(\mathrm{CH}_{2}-\mathrm{O}\right), 76.34$ (acetylenic tertiary carbon), 77.33 (acetylenic quaternary carbon), $102.05\left(\mathrm{C}^{8}\right), 112.28\left(\mathrm{C}^{3}\right), 112.57\left(\mathrm{C}^{6}\right), 114.15$ $\left(\mathrm{C}^{10}\right), 125.54\left(\mathrm{C}^{5}\right), 152.33,154.92\left(\mathrm{C}^{4}, \mathrm{C}^{9}\right), 160.24,160.96$ $\left(\mathrm{C}^{7}, \mathrm{C}^{2}\right)$. For atom numbering see Scheme 1 .

\section{Polymerization}

Polymerization was performed using standard vacuum break-seals techniques. ${ }^{17}$ Molar ratio monomer/ catalyst $=50$ and initial monomer concentration $=0.16$ mol L-1 (Mo-based catalysts) or $0.5 \mathrm{~mol} \mathrm{~L}^{-1}\left(\mathrm{PdCl}_{2}\right)$ were applied. In the case of Mo-based catalysts, $\mathrm{MoCl}_{5}(0.02$ $\mathrm{mmol}$ ) in benzene was mixed with an equimolar amount of cocatalyst $\left(\mathrm{Bu}_{4} \mathrm{Sn}\right.$ or $\mathrm{EtAlCl}_{2}$ in benzene solution) and the mixture was allowed to ripen at room temperature for $15 \mathrm{~min}$ before the monomer addition. During polymerization, the temperature was kept at $60^{\circ} \mathrm{C}$. In the case of $\mathrm{PdCl}_{2}$ catalyst, $\mathrm{PdCl}_{2}(0.02 \mathrm{mmol})$ was mixed with monomer in $\mathrm{DMF}$ at $85^{\circ} \mathrm{C}$ and at this temperature the 
<smiles>C=CCOc1ccc2c(C)cc(=O)oc2c1</smiles>

$\mathrm{PgCo}$

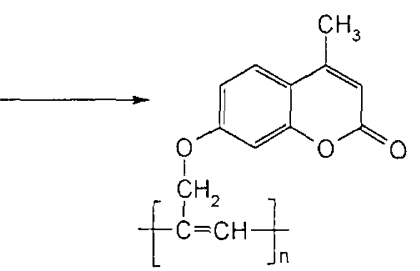

poly $(\mathrm{PgCo})$
Scheme 1.

whole polymerization proceeded. In both cases, red brown precipitate appeared during polymerization. The polymerization was stopped after $8 \mathrm{~h}$ or $24 \mathrm{~h}$ (Mo or $\mathrm{PdCl}_{2}$ catalyst, respectively) by pouring the reaction mixture into an excess of methanol. The methanol insoluble product was separated and dried in vacuum at 40 ${ }^{\circ} \mathrm{C}$. The yield of product was determined gravimetrically.

\section{Techniques}

Size Exclusion Chromatography (SEC) analysis was made at room temperature using a TSP (Thermo Separation Products, Florida, USA) chromatograph fitted with UV detector (operating at $\lambda=254 \mathrm{~nm}$ ). One PL-gel column (Mixed E, Polymer Laboratories, UK) and freshly distilled $\mathrm{CHCl}_{3}$ (flow rate $0.4 \mathrm{ml} \mathrm{min}^{-1}$ ) were used. Molecular weights relative to polystyrene standards are reported.

IR spectra were recorded on a Nicolet Impact 410 spectrometer in $\mathrm{KBr}$ pellets, UV-Vis spectra on a Hewlett-Packard HP 89500 spectrometer in $\mathrm{CHCl}_{3} \cdot{ }^{13} \mathrm{C}$ and ${ }^{1} \mathrm{H}$ NMR spectra of monomer and polymer were recorded on a UNITY-200 and UNITY-500 Varian NMR spectrometer, respectively, in $\mathrm{CDCl}_{3}$ solvent with $1 \%(\mathrm{v} /$ v) of hexamethyldisilane added as internal standard for ${ }^{1} \mathrm{H}(\delta=0.04 \mathrm{ppm}) .{ }^{13} \mathrm{C}$ spectra were referenced to a central line of the solvent triplet ( $\delta=76.99 \mathrm{ppm}$ ). Selective decoupling was used to assign peaks in a ${ }^{1} \mathrm{H}$ spectrum of monomer. DEPT multiplicity editation and HETCOR allowed us to assign majority of ${ }^{13} \mathrm{C}$ NMR lines of monomer. Assignment from the literature ${ }^{7}$ was also taken into account.

A laser kinetic spectrometer (Applied Photophysics, UK) as well as the details of measurement of fluorescence and difference absorption spectra have been described elsewhere. ${ }^{18,19}$ Transient species (excited singlet and triplet states, radical cation) were generated by a Lambda Physik LPX 205 excimer laser $\left(\lambda_{\text {exc }}=308 \mathrm{~nm}\right.$, pulse length $28 \mathrm{~ns}$, energy $1-5 \mathrm{~mJ}^{\text {pulse }}{ }^{-1}$ ). Fluorescence response and absorbance changes in time at the selected wavelength were detected using an R928 photomultiplier (Hamamatsu). The spectra were calculated point-by-point by mathematical treatment of the recording, i.e., by integration of the time dependence of fluorescence (fluorescence spectra) and by extraction of absorbance values at the selected time (absorption spectra).

\section{RESULTS AND DISCUSSION}

Polymerization of 7-propargyloxy-4-methylcoumarin $(\mathrm{PgCo})$ is described by the following Scheme 1. Two different catalytic systems were applied for polymeriza-

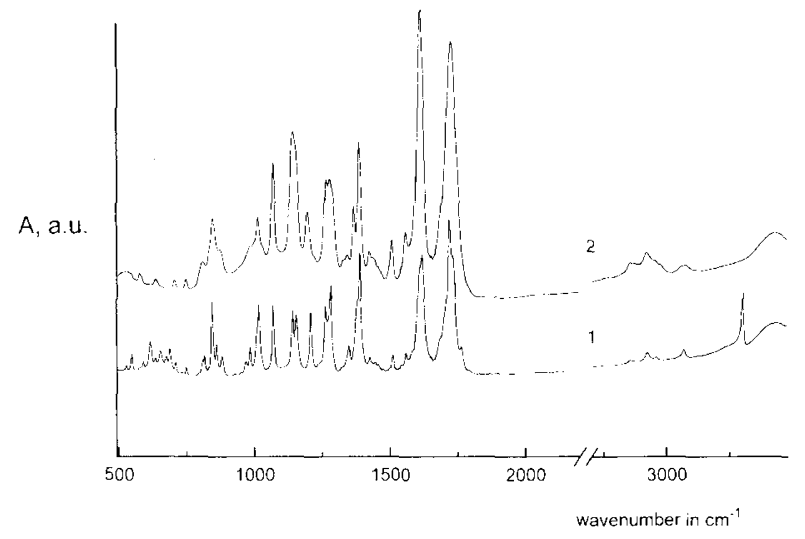

Figure 1. IR spectrum of $\mathrm{PgCo}(1)$ and poly( $\mathrm{PgCo})$ prepared with $\mathrm{PdCl}_{2}(2)$.

tion: (i) $\mathrm{MoCl}_{5}$ combined with $\mathrm{Bu}_{4} \mathrm{Sn}$ or $\mathrm{EtAlCl}_{2}$ cocatalysts in benzene, (ii) $\mathrm{PdCl}_{2}$ in $\mathrm{DMF}$. The reaction conditions (see EXPERIMENTAL) corresponding with those for the best polymerization of substituted phenyl propargyl ethers (studied previously ${ }^{13,14}$ ) were chosen. As methanol insoluble products, $\mathrm{MoCl}_{5} / \mathrm{Bu}_{4} \mathrm{Sn}$ and $\mathrm{MoCl}_{5} / \mathrm{EtAlCl}_{2}$ systems provided brown solids in yields of $57 \%$ and $50 \%$, respectively. The polymers are insoluble in tetrahydrofuran (THF) and aromatics but soluble in $\mathrm{CHCl}_{3}$ (product prepared with $\mathrm{EtAlCl}_{2}$ cocatalyst is soluble only in hot chloroform). Their IR spectra lack bands characteristic of $\mathrm{C} \equiv \mathrm{CH}$ groups but contain bands characteristic of coumarin skeleton. SEC in $\mathrm{CHCl}_{3}$ showed that the product prepared with $\mathrm{Bu}_{4} \mathrm{Sn}$ cocatalyst consists of three fractions with narrow symmetrical peaks $\left(M_{p}=2100\right.$, $52 \% ; M_{\mathrm{p}}=1400,19 \%$ and $M_{\mathrm{p}}=900,26 \% ; M_{\mathrm{p}}=$ molecular weight corresponding to the SEC peak apex, percentage by SEC record area). These peaks were not sufficiently base-line separated that made impossible precise $M_{w}$ and $M_{n}$ determination. Attempts to strip the higher molecular weight fraction from the lower ones were not successful.

$\mathrm{PdCl}_{2}$ in DMF provided a light brown solid as a methanol insoluble product (yield of $59 \%$ ), soluble in $\mathrm{CHCl}_{3}$ and DMF and its SEC (in $\mathrm{CHCl}_{3}$ ) showed a low molecular weight polymer peak $\left(M_{w}=6400, M_{n}=\right.$ $4600 ; 68 \%$ of total SEC area) accompanied by a narrow oligomer peak $\left(M_{\mathrm{p}}=1300\right)$. The oligomer was washed out from the polymer with THF. IR spectrum of purified polymer (Figure 1) is very close to the spectra of samples prepared with Mo-based catalysts and suggests the polymerization to proceed via transformation of $\mathrm{C} \equiv \mathrm{CH}$ bonds according to Scheme $1 .{ }^{1} \mathrm{H}$ NMR of polymer (Figure 2a) shows following signals : strong, rather narrow signal at $2.3 \mathrm{ppm}\left(\mathrm{CH}_{3}\right)$, two broad signals in the region $3.6-5.0 \mathrm{ppm}\left(\mathrm{CH}_{2}-\mathrm{O}\right)$ and three broad signal in the region from 5.8 to $7.6 \mathrm{ppm}$ corresponding to coumarin protons (for their numbering see Scheme 1). Signals of the main chain protons are expected to be broad and be overlapped by signals of aromatic protons. ${ }^{13} \mathrm{C}$ NMR spectrum (Figure 2b) shows signals at $18.7 \mathrm{ppm}\left(\mathrm{CH}_{3}\right)$, broad doublet in the region $62-76 \mathrm{ppm}\left(-\mathrm{O}-\mathrm{CH}_{2}\right)$, signals of coumarin carbons (for numbering see Scheme 1) and broad signal in the region $128-140 \mathrm{ppm}$ corresponding to the main chain carbons. Neither ${ }^{1} \mathrm{H}$ nor ${ }^{13} \mathrm{C} N M R$ spectrum contain signals of acetylenic groups. There- 
(a)

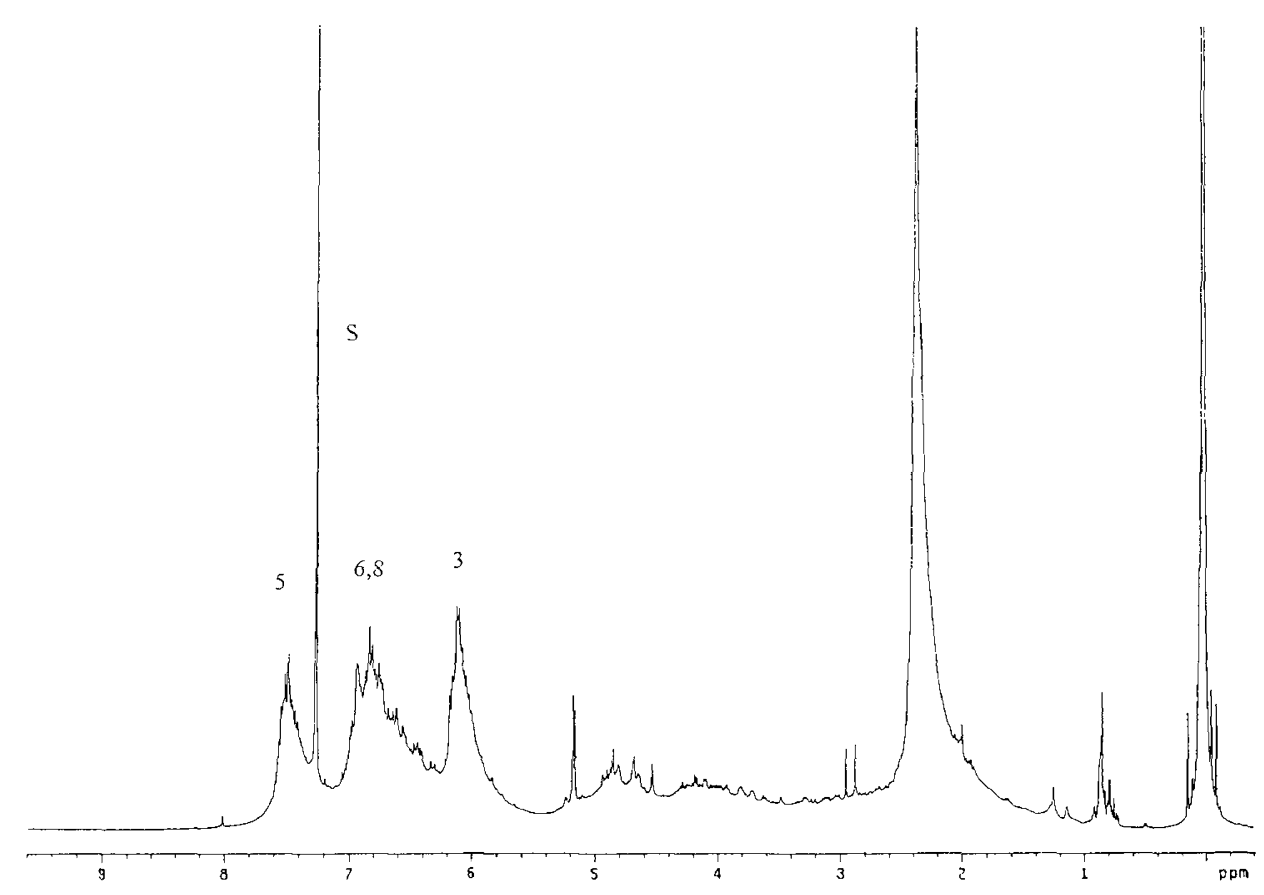

(b)

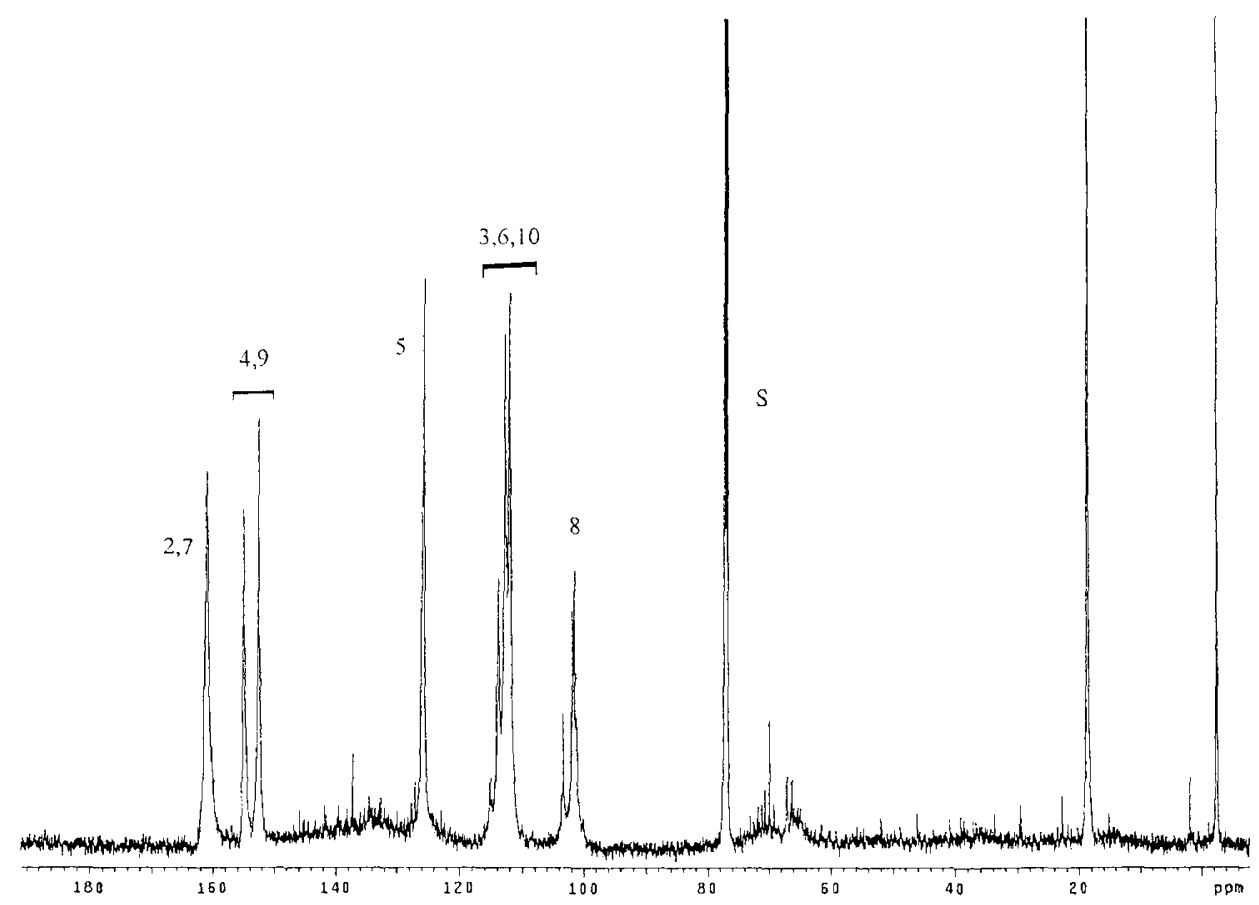

Figure 2. ${ }^{1} \mathrm{H}$ (a) and ${ }^{13} \mathrm{C}$ NMR spectra (b) of poly $\left(\mathrm{PgCo}\right.$ ) prepared with $\mathrm{PdCl}_{2}$. S-solvent signal, for signal numbering see Scheme 1.

fore, the spectra are in accord with the polymer structure given in Scheme 1. The line broadening indicates low polymer stereoregularity. The splitting of $\mathrm{O}-\mathrm{CH}_{2}$ signal in both spectra (observed also for some poly(phenyl propargyl ether) $\mathrm{s}^{13,14,20}$ ) may be related to different configurations of polymer main chain (cf. splitting of ${ }^{13} \mathrm{C}$ methylene and methyl signals in poly(1-butyne ${ }^{21}$, but any detailed information about geometric structure of poly $(\mathrm{PgCo})$ molecule cannot be obtained from spectroscopic data.

UV-Vis spectra of PgCo and its polymer poly(PgCo) prepared with $\mathrm{PdCl}_{2}$ are given in Figure 3. The transformation of $\mathrm{PgCo}$ into polyacetylene-type poly $(\mathrm{PgCo})$ is evidenced by the band tailing in the vis-part of polymer spectrum (above $350 \mathrm{~nm}$ ). However, the shape and position of this band tailing suggest that the average effective conjugation length of polymer main chain is rather low. UV-Vis spectra of products prepared with $\mathrm{MoCl}_{5} /$ $\mathrm{Bu}_{4} \mathrm{Sn}$ and $\mathrm{MoCl}_{5} / \mathrm{EtAlCl}_{2}$ catalyst systems are similar to the polymer spectrum in Figure 3, indicating that the main chain conjugation length of polymers prepared with these catalysts is probably also low.

Figure 4 shows emission fluorescence spectra of $\mathrm{PgCo}$ and poly( $\mathrm{PgCo}$ ) samples in $\mathrm{CHCl}_{3}$. Significant red shift $(\sim 55 \mathrm{~nm})$ and band broadening in fluorescence spectrum of polymer are evident (contrary to the situation in 


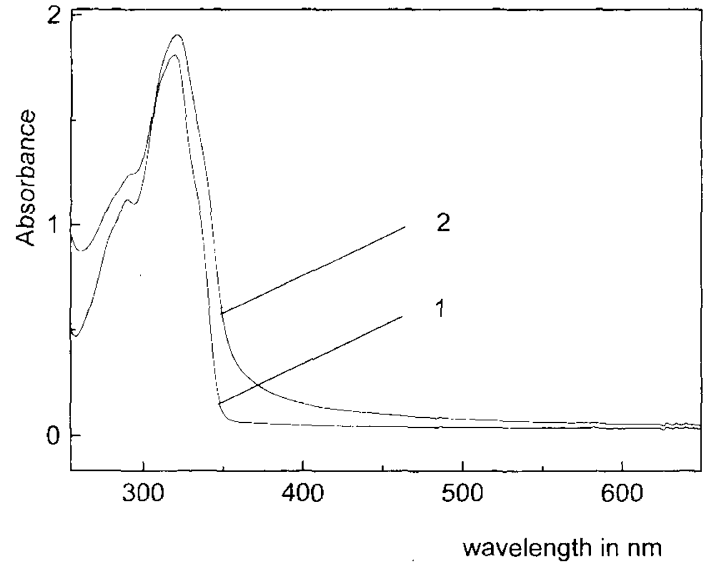

Figure 3. UV-Vis spectrum of $\mathrm{PgCo}(1)$ and poly $(\mathrm{PgCo})$ prepared with $\mathrm{PdCl}_{2}(2) . \mathrm{CHCl}_{3}, c=0.25 \mathrm{mg} \mathrm{mL}{ }^{-1}, l=0.1 \mathrm{~cm}$.

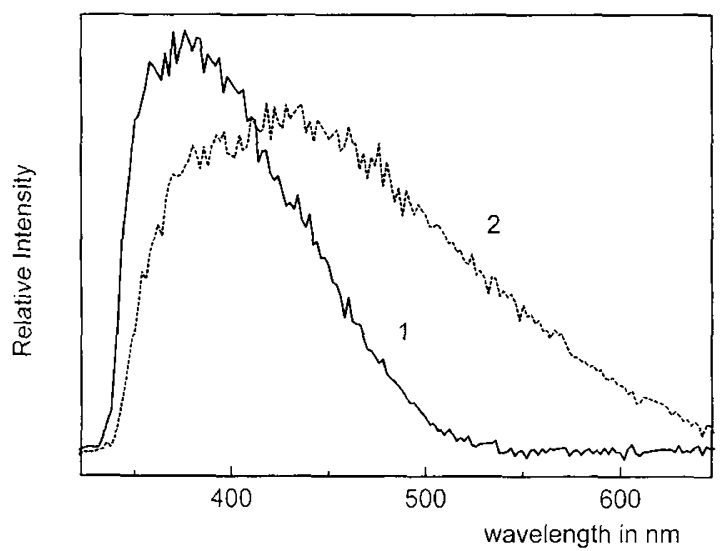

Figure 4. Fluorescence emission spectra of $\mathrm{PgCo}$ (1) and poly(PgCo) prepared with $\mathrm{PdCl}_{2}(2) . \mathrm{CHCl}_{3}, c=0.06 \mathrm{mg} \mathrm{mL}^{-1}$.

coumarin-containing polynorbornene and some polyacrylates, where monomers show essentially the same emission spectra as polymers ${ }^{7,22}$ ). As polymers from alkyl or aryl monosubstituted acetylenes do not usually exhibit intensive fluorescence, ${ }^{12}$ this shift for poly $(\mathrm{PgCo})$ indicates strong interaction between individual coumarin groups in the polymer and/or between coumarin groups and polymer backbone. We were not able to analyze the kinetics of the fluorescence decay because the lifetime of the excited singlet states ( $\tau_{\mathrm{S}} \ll 5 \mathrm{~ns}$ ) was bellow the length of the excitation pulse $(\sim 28 \mathrm{~ns})$.

Two transient species were found in difference absorption spectra of PgCo (Figure 5, curve 1) after excitation by a laser pulse. These results are in good agreement with previous literature reports for coumarins. ${ }^{23,24}$ The transient with $\lambda_{\max }=480 \mathrm{~nm}$ was quenched by oxygen and assigned to the triplet states with lifetime $\tau_{\mathrm{T}}=2.6$ $\pm 0.1 \mu \mathrm{s}$ in argon-saturated $\mathrm{CHCl}_{3}$. The triplet states are formed by intersystem crossing from the excited singlet states. The radical cation $\left(\lambda_{\max }=375 \mathrm{~nm}\right)$ was generated by direct photoionization and decayed by mixed kinetics with lifetimes $\tau_{\mathrm{RC}} \sim 1-5 \mu \mathrm{s}$. In contrast, formation of radical cations in polymer with positive charges on coumarin units was negligible in comparison with PgCo monomer (Figure 5, curve 2). The reason for the instability of such structures may be the strong Cou-

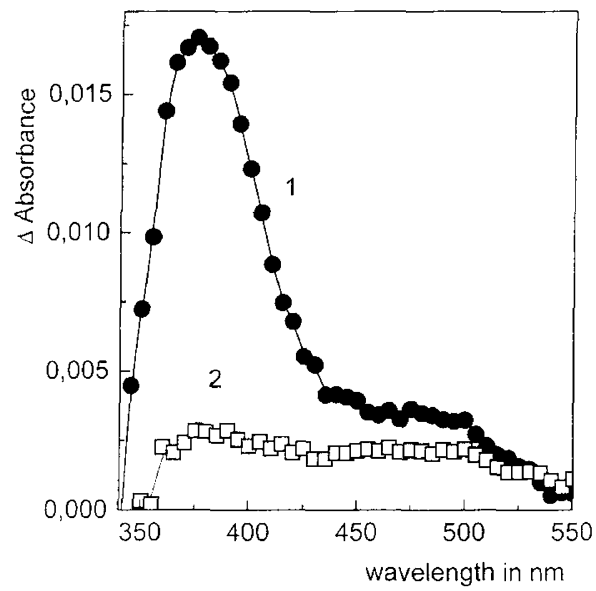

Figure 5. Difference absorption spectra of PgCo (1) and poly(PgCo) prepared with $\mathrm{PdCl}_{2}$ (2). $200 \mathrm{~ns}$ after excitation pulse. $\mathrm{CHCl}_{3}, c=0.06 \mathrm{mg} \mathrm{mL}^{-1}$.

lombic repulsion between coumarin pendant groups. Incorporation of PgCo into polymer did not significantly influence formation of the triplet states $\left(\lambda_{\max }=480 \mathrm{~nm}\right.$, $\left.\tau_{\mathrm{T}}=5.8 \pm 0.1 \mu \mathrm{s}\right)$. The longer lifetime of the triplet state has been clarified by Dexter-type of energy transfer between adjacent aromatic groups in polymer. ${ }^{25}$ The triplet energy migration involves a short interaction of coumarin chromophores with overlapping of electronic charge clouds. Incomplete knowledge of polymer microstructure does not allow us to obtain more detailed information about interactions between coumarin groups and polymer conjugated backbone.

Acknowledgments. Financial support from the Grant Agency of the Czech Republic (grant No. 203/98/1165) is gratefully acknowledged.

\section{REFERENCES}

1. T. Wakimoto, Y. Yonemoto, J. Funaki, M. Tsuchida, R. Murayama, H. Nakada, H. Matsumoto, S. Yamamura, and M. Nomura, Synt. Met., 91, 15 (1997).

2. E. Gautierthianche, C. Sentein, J. M. Nunzi, A. Lorin, C. Denis, and P. Raimond, Synt. Met., 91, 323 (1997).

3. S. Fomine, L. Fomina, C. Sanchez, A. Ortis, and T. Ogawa, Polym.J., 29, 49 (1997).

4. S. Fomine, H. Perez, L. Fomina, M. Tlenkopatchev, and T. Ogawa, Macromol. Chem. Phys., 198, 1679 (1997).

5. S. Fomine, C. Delgado, L. Fomina, R. Gavino, and T. Ogawa, Macromol. Chem. Phys., 198, 3065 (1997).

6. S. Fomine, E. Rivera, L. Fomina, A. Ortiz, and T. Ogawa, Polymer, 39, 15 (1998).

7. M. Tlenkopatchev, S. Fomine, L. Fomina, R. Gavino, and T. Ogawa, Polym. J., 29, 622 (1997).

8. M. Uchida, T. Izumizava, and K. Furukawa, Eur. Pat 661366. Chem. Abstr., 123, 241426 (1995).

9. Y. Chen, R. Wehrmann, A. Elschner, and R. Dujardin, Ger. Offen, DE 19505942. Chem. Abstr., 125, 248827 (1996).

10. G. A. Lindsay, J. M. Hoower, D. R. Yankelevich, and A. Knoesen, Polym. Prepr., Am. Chem. Soc., Div. Polym. Chem., 34, 771 (1993).

11. A. R. A. Palmans, P. Smith, and C. Weder, Macromolecules, 32, 4677 (1999).

12. K. Tada, R. Hidayat, M. Hirohata, M. Teraguchi, T. Masuda, and K. Yoshino, Jpn. J. Appl. Phys., 35, L1138 (1996).

13. H. Balcar, T. Kalisz, J. Sedlácek, V. Blechta, and P. Matějka, Polymer, 39, 4443 (1998). 
14. H. Balcar, P. Holler, J. Sedláček, and V. Blechta, Collect. Czech. Chem. Commun., 63, 1803 (1998).

15. K. Mach, Collect. Czech. Chem. Commun., 30, 277 (1965).

16. J. Vohlídal, A. Hollander, M. Jancálková, J. Sedláček, and I. Sargánková, Collect. Czech. Chem. Commun, 56, 351, (1991).

17. H. Balcar, A. Dosedlová, V. Hanuš, L. Petrusová, and B. Matyska, Collect. Czech. Chem. Commun., 49, 1737 (1984).

18. P. Kubát, M. Jirsa, and Z. Zelinger, Radiat. Res., 148, 382 (1997).

19. K. Lang, D. M. Wagnerová, P. Engst, and P. Kubát, Chem. Soc., Faraday Trans. II, 88, 677(1992).

20. W. Ch. Lee, Y. S. Gal, S. H. Jin, S. J. Choi, H. J. Lee, and S.
K. Choi, J. Macromol. Sci., Pure Appl. Chem., A31, 737 (1994).

21. T. Masuda, Y. Okano, K. Tamura, and T. Higashimura, Polymer, 26, 793 (1985).

22. G. Jones II and M. A. Rahman, J. Phys. Chem., 98, 13028 (1994).

23. P. W. Wood and L. Johnson, J. Phys. Chem., A, 102, 5587 (1998).

24. R. Becker, S. Chakravorti, C. A. Gardner, and M. Maria de Graca, J. Chem. Soc., Faraday Trans., 89, 1007 (1993).

25. K. Hisada, S. Ito, and M. Yamamoto, J. Phys. Chem., B, 102, 4075 (1998). 